\title{
Psychiatric genetics in South Africa: cutting a rough diamond
}

\author{
GEB Wright', DJH Niehaus², L Koen², BI Drögemöller', L Warnich' \\ 1Department of Genetics, Stellenbosch University, South Africa \\ 2Department of Psychiatry, Stikland Hospital, Stellenbosch University, South Africa
}

\section{Abstract}

Psychiatric disorders place a considerable healthcare burden on South African society. Incorporating genetic technologies into future treatment plans offers a potential mechanism to reduce this burden. This review focuses on psychiatric genetic research that has been performed in South African populations with regards to obsessive-compulsive disorder, schizophrenia and bipolar disorder. Preliminary findings from these studies suggest that data obtained in developed countries cannot necessarily be extrapolated to South African population groups. Psychiatric genetic studies in South Africa seem to involve relatively low-cost methodologies and only a limited number of large national collaborative studies. Future research in South Africa should therefore aim to incorporate highthroughput technologies into large scale psychiatric studies through the development of collaborations. On a global level, the vast majority of psychiatric genetic studies have been performed in non-African populations. South Africa, as the leading contributor to scientific research in Africa, may provide a foundation for addressing this disparity and strengthening psychiatric genetic research on the continent. Although the elucidation of the genetic architecture of psychiatric disorders has proved challenging, examining the unique genetic profiles found in South African populations could provide valuable insight into the genetics of psychiatric disorders.
\end{abstract}

Keywords: Bipolar disorder; Obsessive-compulsive disorder; Pharmacogenetics; Psychiatric genetics; Schizophrenia; South African populations

Received: 23-06-2011

Accepted: 06-07-201 1

doi: http://dx.doi.org/10.4314/ajpsy.v14i5.2

\section{Introduction}

Determining the hereditary basis of psychiatric disorders could yield insight into their pathophysiology and therefore provide opportunities to develop novel treatments. The rich genetic diversity found in African populations offers the potential to better understand the genetic component of complex disorders such as these. Despite this fact, African populations remain underrepresented in genetic research pertaining to psychiatry and drug response, and Africa continues to be the poorest global contributor to international research in the biomedical arena. ${ }^{1}$ On a continental level, South Africa makes the most significant contribution to the biomedical field in Africa ${ }^{2}$ and was responsible for approximately half of such publications from Sub-Saharan Africa between 1995 and 2004. ${ }^{3}$ A survey by Patel and Sumathipala ${ }^{4}$ observed similar results in psychiatric research, finding that $<1 \%$ of articles in a selection of high-

\section{Correspondence}

Prof. LWarnich

Department of Genetics, Stellenbosch University

Private bag X1, Matieland, 7602, South Africa

Tel: +27 218085888 / Fax: +21 218085833

email: Iw@sun.ac.za impact psychiatric journals were of African origin. South Africa, however, has been ranked in the top five of low- and middleincome countries in terms of psychiatric research. ${ }^{5}$ These statistics reiterate the fact that South Africa is the most likely to develop a platform for psychiatric research in Africa. This review will focus on the fields of psychiatric genetics and the accompanying field of psychiatric pharmacogenetics in South Africa, and will discuss the work that needs to be performed in order to begin to bridge the gap between Africa and the developed world in this regard.

South Africa's diverse ethnic groups are ideal for performing various types of genetic studies. According to recent population estimates, South Africa is home to over 48 million people. Eleven official languages are spoken by the country's inhabitants, of whom 79\% are black Africans, 9\% are Caucasians, a further 9\% belong to the Mixed Ancestry (Coloured) population and 3\% are classified as Indian or Asian

(http://www.statssa.gov.za/publications/

P0302/P03022008.pdf). This assortment comprises of populations that range from genetically homogenous (suited to performing case-control association studies) to genetically diverse (suited to fine mapping of susceptibility loci, as well as appropriate for identifying novel genetic variants, e.g 
pharmacogenetic studies). The Afrikaners are an example of a homogenous population as they arose from a small founder population of 1000-2000 Dutch immigrants that arrived in South Africa in the 17th century. 6,7 The ancient southern African Khoisan population possesses the highest level of genetic diversity reported to date, while the Mixed Ancestry population shows the greatest global admixture of any of the world's populations analysed thus far. ${ }^{8}$ Additionally, the Nguni-speaking Xhosa population shows a significant genetic contribution from the Khoisan in their genomes, reflecting admixture between these ancient individuals and ancestral Bantu populations; artefacts of this exchange are also linguistically evident through the click consonants present in the isiXhosa language.,89

The prevalence of psychiatric disorders in the different ethnic groups of South Africa is not known, although evidence from the South African Stress and Health Study ${ }^{10}$ suggests very little difference from non-African populations. However, alarmingly, it appears that the majority of individuals suffering from psychiatric disorders in South Africa do not receive treatment. ${ }^{11}$ Revised burden of disease estimates place neuropsychiatric disorders as the third highest cause of disability-adjusted life years in the country, mainly due to the extended morbidity of such conditions. ${ }^{12}$ Unipolar depression, alcohol use, bipolar affective disorder, schizophrenia, drug use, obsessive-compulsive disorder (OCD) and panic disorder are neuropsychiatric disorders that fall into the top 20 causes of years lived with disability in South Africa. ${ }^{12}$ This is exacerbated by the fact that the pharmacological treatment of these disorders is often inadequate and limited South African data exists for adverse drug reactions ( $\mathrm{ADRs}$ ) and drug inefficacy during the treatment of such conditions. Mehta et al..$^{13}$ found that ADRs were detected in 14\% of patients treated in a South African hospital in Cape Town. It was found that $46 \%$ of these ADRs were regarded as preventable and that $1.5 \%$ of community-acquired ADRs resulted in fatality. When compared to an extensive meta-analysis of the incidence of ADRs in United States (US) hospitals, the ADR rate as well as the rate of fatal ADRs was much higher in South Africa (6.7\% versus $14.0 \%$ and $0.3 \%$ versus $1.5 \%$, respectively). ${ }^{14}$ Elucidating the genetic architecture of psychiatric disorders and designing tailor-made pharmaceutical treatment plans would therefore improve the quality of life for affected individuals and their caregivers in South Africa.

The heritability of the majority of the psychiatric disorders is believed to be high, but similar to many complex diseases, the actual genetic mechanisms that underlie them remain to be established and susceptibility is believed to occur as a result of an intricate interaction between a number of genes and the environment. Traditional candidate gene studies have often produced contradictory findings, while genome-wide association studies (GWAS) have only explained a fraction of the heritability of such disorders. ${ }^{15}$ This review will focus on psychiatric genetic research into schizophrenia, OCD and bipolar disorder in South African populations with reference to global research, as the vast majority of South African research to date has been performed on these disorders. A glossary of relevant genetic terminology discussed in this review can be found in Table I.

\section{Schizophrenia}

Schizophrenia is a chronic psychiatric disorder characterised by positive (i.e. hallucinations and delusions) and negative (e.g. anhedonia, avolition, alogia and blunted affect) symptoms, a lifetime prevalence rate of roughly $1 \%$ and a high heritability (reviewed by Van Os \& Kapur ${ }^{16}$ ). Studies investigating the genetic susceptibility to this disorder in South African populations have predominantly been performed by foreign researchers. Riley and collaborators were the first to investigate schizophrenia in a South African population and published a series of manuscripts on linkage analyses in a cohort of Bantu-speaking black South Africans. ${ }^{17-22}$ Areas of implied linkage to schizophrenia identified by these studies are displayed in Table II and include genomic regions surrounding the coding regions for subunits of N-methylD-aspartate (NMDA) receptors ${ }^{19}$ and the alpha7 acetylcholine receptor gene (CHRNA7).22 NMDA receptors form part of the glutamate system, which is believed to be of relevance as NMDA antagonists (i.e. phencyclidine) cause effects similar to the positive and negative symptoms of schizophrenia. ${ }^{23}$ Genetic variants of the CHRNA7 gene have been found to be linked to impaired response to auditory stimuli, frequently observed in schizophrenia patients. ${ }^{24}$ The small sample sizes of these studies involving a cohort of black South African individuals that were broadly classified as Bantuspeaking, however, indicate that these findings should be interpreted with caution, as highlighted by a recent meta-analysis of genome-wide linkage studies of schizophrenia. ${ }^{25}$

To date, some of the most significant research into the genetic component of psychiatric disorders in South African populations has been performed in the Afrikaner schizophrenia population. This group of individuals is largely homogenous (environmentally and genetically) and are therefore less likely to present with confounding factors in genetic epidemiology studies (e.g. population stratification). ${ }^{\text {? }}$ Since the Afrikaners are a founder population established in the 17th to 18th centuries, linkage disequilibrium (LD) in their genomes extends over further distances than in other populations, including genetically isolated populations such as the Finns and the Sardinians. ${ }^{26}$ This therefore aids in the identification of regions of the genome that contribute towards complex traits such as schizophrenia.

Chromosomal locations that have been identified to be putatively linked to the disorder in the Afrikaner schizophrenia group can also be found in Table II.27-29 The region on chromosome 22ql l is of particular significance for schizophrenia research, as hemizygous microdeletions of this region cause $22 \mathrm{q} l \mathrm{l}$ deletion syndrome (22ql lDS) $)^{30}$, a syndrome with an elevated prevalence of psychiatric disorders such as schizophrenia (i.e. 25-30\%, compared with a prevalence of $1 \%$ in the general population). ${ }^{31,32}$ Over 35 genes are deleted in the majority of 22qDS patients, which has lead to the hypothesis that haploinsufficiency of one or more of these genes may contribute to the increased risk for schizophrenia in these individuals. ${ }^{30}$ Approximately $1 \%$ of schizophrenia patients are believed to harbour 22ql 1 deletions ${ }^{32}$ and in the Afrikaner population, Wiehahn et al. ${ }^{33}$ noted, in a small cohort of schizophrenia patients ( $\mathrm{n}=85)$, that $2.4 \%$ of cases possessed $22 \mathrm{q} 11$ deletions.

The importance of rare copy number variation (CNV) in Afrikaner schizophrenia patients was recently confirmed by two studies. ${ }^{29,34}$ De novo CNV mutations were found to be approximately eight times more frequent in sporadic schizophrenia cases when compared to healthy controls. Deletions of the 22ql l locus were detected in three sporadic cases, confirming this region as the most reproducible, highly penetrant CNV mutation contributing towards schizophrenia- 
Table I. Glossary of genetic terminology

\begin{tabular}{|c|c|}
\hline Allele & $\begin{array}{l}\text { An alternative form of a gene caused by change in the DNA sequence at a particular chromosomal position. CYP gene } \\
\text { alleles are designated with an asterisk (i.e. *) and should contain polymorphisms that "affect transcription, splicing, } \\
\text { translation, posttranscriptional or posttranslational modifications or result in at least one amino acid change } \\
\text { (www.cypalleles.ki.se)". }\end{array}$ \\
\hline Candidate gene study & $\begin{array}{l}\text { A genetic study involving a gene thought to be implicated in a particular phenotype (e.g. disease of interest). This is usually } \\
\text { based on prior evidence suggesting that the protein may be involved with that phenotype, or linkage data showing an } \\
\text { association with the chromosomal region where the candidate gene is located. }\end{array}$ \\
\hline Copy number variation (CNV) & $\begin{array}{l}\text { Deletion or duplication of chromosomal segments greater than } 1 \mathrm{~kb} \text { in size, which may contain genes, and are caused by } \\
\text { non-homologous recombination. }\end{array}$ \\
\hline $\begin{array}{l}\text { Genome-wide association } \\
\text { study (GWAS) }\end{array}$ & $\begin{array}{l}\text { Genomic studies where several hundred thousand variants, spanning the genome, are assayed on 'SNP chips'. Unlike } \\
\text { candidate gene studies, GWAS has the power to detect associations with genes/pathways that are not previously thought } \\
\text { to be associated with the phenotype of interest. Such studies usually follow a case-control design, where allele frequency } \\
\text { differences between the two cohorts are tested for significance. }\end{array}$ \\
\hline Genotype & $\begin{array}{l}\text { The genetic composition of an organism or the allelic makeup of an individual. A homozygous genotype refers to a sample } \\
\text { with two identical alleles, while a heterozygous one describes a sample with two different alleles. }\end{array}$ \\
\hline Haploinsufficiency & $\begin{array}{l}\text { The situation where an individual possess only one functional copy of a gene, where two functional copies are require to } \\
\text { express enough of the respective protein for normal functioning. }\end{array}$ \\
\hline Haplotype & Combinations of variants that are inherited together. \\
\hline Linkage study & $\begin{array}{l}\text { A family-based genetic study that examines the co-segregation of the phenotype of interest with genetic markers to identify } \\
\text { relevant chromosomal regions. These data are subsequently used to identify positional candidate genes. }\end{array}$ \\
\hline Linkage disequilibrium (LD) & $\begin{array}{l}\text { The process where variants on the same chromosome tend to occur together in a non-random manner (i.e. segregate with } \\
\text { one another). } L D \text { is caused when a new mutation occurs on a stretch of DNA on a chromosome that is in close proximity to } \\
\text { another variant and tends to decay over time due to recombination. }\end{array}$ \\
\hline Microsatellite markers & $\begin{array}{l}\text { A highly variable type of genetic marker that consists of nucleotide repeats, usually di-, tri- or tetranucleotide in nature. } \\
\text { Microsatellites have been frequently used in linkage studies. }\end{array}$ \\
\hline Next generation sequencing & $\begin{array}{l}\text { A recent type of sequencing technology that allows for high-throughput sequencing of millions of DNA sequences in a short } \\
\text { amount of time. Advances in this arena have applications in personalised medicine, allowing for whole genomes as well as } \\
\text { exomes (i.e. coding region of the genome) to be generated in less than a week, at a dramatically reduced cost when } \\
\text { compared to traditional methods. }\end{array}$ \\
\hline $\begin{array}{l}\text { Pharmacogenetics and } \\
\text { pharmacogenomics }\end{array}$ & $\begin{array}{l}\text { Pharmacogenetics and pharmacogenomics involve the study of the genetic determinants of drug response. } \\
\text { Pharmacogenetic research focuses on individual genes/alleles, while pharmacogenomics involves the analysis of the entire } \\
\text { genome. }\end{array}$ \\
\hline Phenotype & The observable characteristics (physical or biochemical) of an organism. \\
\hline Population stratification & $\begin{array}{l}\text { A confounding factor in genetic studies, where there are ancestry differences between cases and controls. Differences in } \\
\text { allele frequencies may therefore be caused by differences in ancestry and not the phenotype of interest, resulting in } \\
\text { spurious associations. }\end{array}$ \\
\hline $\begin{array}{l}\text { Single nucleotide } \\
\text { polymorphism (SNP) }\end{array}$ & $\begin{array}{l}\text { A point mutation (i.e. DNA base change affecting a single nucleotide) in the genome. SNPs are catalogued on the dbSNP } \\
\text { database (http://www.ncbi.nlm.nih.gov/snp/) using unique reference SNP (rs) identification numbers. }\end{array}$ \\
\hline
\end{tabular}

susceptibility identified to date. ${ }^{34}$ Conversely, familial cases of schizophrenia were subsequently shown to have a higher frequency of inherited rare CNV mutations when compared to unaffected individuals. These findings emphasize the heterogeneous nature of the disorder, as susceptibility to familial and sporadic schizophrenia may be caused by different genomic regions or mechanisms. ${ }^{29}$

Studies have shown that Afrikaner schizophrenia patients are clinically comparable to Caucasian patients diagnosed in the US. ${ }^{7,35}$ It is, however, also important to investigate indigenous black African populations if the benefits of molecular medicine are to be realised in all of South Africa's population groups. Our research group has therefore focussed predominantly on schizophrenia subjects from the South African Xhosa population. Although the core symptomatology of Xhosa schizophrenia patients appears to be similar to Caucasian schizophrenia patients ${ }^{36}$, there are clinical differences between Xhosa schizophrenia patients and those of European descent (e.g. Afrikaners). Considerably less Xhosa patients present with comorbid OCD when compared to Afrikaner cases (0.5\% versus 10.7\% respectively). ${ }^{36,37}$ Additionally, to date, no Xhosa schizophrenia patients have been found to carry $22 \mathrm{q} l 1$ microdeletions, indicating that CNV at this locus may not contribute to schizophreniasusceptibility in this population. ${ }^{38}$ It should also be noted that one of the studies of a Bantu-speaking schizophrenia cohort 


\begin{tabular}{|c|c|c|c|c|}
\hline Chromosome & Disorder & Gene locus & Population & Reference \\
\hline 1 & SCZ, BD & / & Afrikaners, SA Caucasians & {$[27,29,74]$} \\
\hline 9 & SCZ & GRIN1 & SA Bantu & {$[19]$} \\
\hline 10 & $B D$ & / & SA Caucasians & {$[74]$} \\
\hline 12 & SCZ & GRIN2B & SA Bantu & {$[19]$} \\
\hline 13 & SCZ & / & Afrikaners, SA Bantu & {$[21,27,29]$} \\
\hline 15 & SCZ & CHRNA7 & SA Bantu & {$[22]$} \\
\hline 16 & $B D$ & / & SA Caucasians & {$[74]$} \\
\hline 17 & $\mathrm{SCZ}$ & GRIN2C & SA Bantu & {$[19]$} \\
\hline 22 & SCZ & PRODH2-DGCR6 & Afrikaners & {$[28]$} \\
\hline
\end{tabular}

BD, bipolar disorder; SA, South Africa; SCZ, schizophrenia

thus increasing the chances of identifying causative genes. A putative endophenotype that has been studied in the Xhosa schizophrenia population is the impairment of facial affect recognition when compared to healthy control individuals. Xhosa schizophrenia patients and their unaffected siblings have difficulties recognising faces displaying negative emotions (i.e. anger), yet show normal recognition to positive emotions (i.e. happiness). ${ }^{42,43}$ This deficit could serve as a neurocognitive endophenotype that could be investigated in future schizophrenia genetic studies in the Xhosa population.

\section{Obsessive-compulsive disorder (OCD)}

OCD is an anxiety disorder that is characterised by obsessions (unwanted, recurrent thoughts or

mentioned earlier, found no evidence for $22 \mathrm{q}$ linkage. ${ }^{18}$ These data indicate that genetic, as well as cultural, differences exist between the black African Xhosa schizophrenia patients and those of Caucasian ethnicity. Therefore, results obtained from one population cannot necessarily be extrapolated to another.

Studies of genetic susceptibility to schizophrenia in the Xhosa population have investigated polymorphisms in the central nervous system related genes, KCNN3 and PPP2R2B, as well as a gene encoding a mitochondrial protein involved in the antioxidant defence system, MnSOD (also known as SOD2). 39,40 Neither of these studies, utilising cohorts of over 500 samples, however, found significant associations with schizophrenia. Alternative approaches, such as classifying patients by means of measurable heritable internal biomarkers known as endophenotypes, may produce more successful results. ${ }^{41}$ The endophenotype concept has gained popularity in psychiatric genetic research as patients suffering from polygenic disorders such as schizophrenia can be classified into more homogenous groups than with conventional diagnoses (e.g. DSM and ICD), images) and/or compulsions (repetitive behaviours or mental activities), causing marked stress and anxiety for patients (reviewed by Stein ${ }^{44}$ ). The disorder displays heterogeneous symptoms and genetic factors are believed to contribute towards $O C D$ susceptibility (from $O C D$ twin study data: heritability reported to be between $45-60 \%$ in children and $27-45 \%$ in adults). ${ }^{45}$ Despite the fact that a number of OCD candidate gene studies have been conducted, inconsistent results have been obtained (reviewed by Nicolini et al. ${ }^{46}$ ). In South Africa, the majority of research into the genetic susceptibility of the disorder has been performed in the South African Caucasian population, including the Afrikaner population. In line with international research, these studies have predominantly focussed on genes involved in serotoninergic and dopaminergic function. ${ }^{47-58}$ A summary of genes that have been significantly associated on occasion with OCD and related traits in South African populations can be found in Table III.

The serotoninergic genes are believed to be involved in OCD pathogenesis as selective serotonin reuptake inhibitors

\begin{tabular}{|c|c|c|c|c|}
\hline Gene & Polymorphism & Effect & Association & References \\
\hline 5-HT1Db & G861C (rs6296) & Synonymous & OCD-susceptibility (Afrikaner male subgroup) & {$[51]$} \\
\hline $5-\mathrm{HT} 2 \mathrm{~A}$ & T102C (rs6313) & Synonymous & Trichotillomania & {$[56]$} \\
\hline BDNF & Val66Met (rs6265) & Amino acid change & $\begin{array}{l}\text { OCD-susceptibility } \\
\text { Age of OCD onset }\end{array}$ & $\begin{array}{l}{[70]} \\
{[71]}\end{array}$ \\
\hline COMT & Val158Met (rs4680) & $\begin{array}{l}\text { Amino acid change - methionine allele } \\
\text { causes a reduction in enzyme activity }\end{array}$ & $\begin{array}{l}\text { OCD-susceptibility } \\
\text { Hoarding in OCD } \\
\text { OCD- symptomatology }\end{array}$ & \begin{tabular}{|l}
{$[48]$} \\
{$[55]$} \\
{$[58]$}
\end{tabular} \\
\hline DRD4 & $48 \mathrm{bp} \mathrm{VNTR}$ & $\begin{array}{l}\text { Causes proteins that differ in length } \\
\text { (located in exon 3) }\end{array}$ & Age of OCD onset & {$[53]$} \\
\hline MAO-A & C1460T (rs1137070) & Synonymous & $\begin{array}{l}\text { OCD-susceptibility (female subgroup) } \\
\text { Sexual dimorphism }\end{array}$ & {$[51]$} \\
\hline SLC6A4 & 5-HTTLPR & S-allele causes decreased expression & Dissociative experiences in $\mathrm{OCD}$ & {$[57]$} \\
\hline
\end{tabular}


(SSRIs) effectively treat OCD and form the first-line of pharmacotherapy for the disorder. ${ }^{59}$ Genes that have been investigated with regards to OCD in South African populations due to their functional relevance in the serotoninergic system include the serotonin transporter (5-HTT) gene (SLC6A4), two serotonin receptor genes, 5-HT 1 Db (also known as HTRlB) and 5-HT $\mathrm{H}_{2 \AA}$ (also known as HTR2A), and the monoamine oxidase A gene (MAO-A). The SLC6A4 gene is involved in serotonin reuptake at the synapses and variation of this gene has been linked to various psychiatric disorders, including $O C D .{ }^{60} \mathrm{~A}$ functional promoter polymorphism, 5-HTTLPR, has been extensively studied. The resulting alleles differ in transcriptional activity, with the short (S-) allele linked to lower expression of the gene than the long (L-) allele. ${ }^{61}$ In South African OCD studies, this polymorphism has not been associated with susceptibility to the disorder $47,51,56$, yet homozygosity for the S-allele, in conjunction with neglect, was found to be predictive of dissociative experiences in $\mathrm{OCD}$ patients. ${ }^{57}$ Results from a meta-analysis of this polymorphism with regards to OCD-susceptibility, emphasise that the 5HTTLPR polymorphism may be only associated with certain OCD subtypes (e.g. paediatric-onset cases). This may explain the inconsistent results obtained from case-control association studies of this polymorphism. ${ }^{60}$

With regards to the serotonin receptor genes: (i) the genotype distribution of the 5-HT 1 Db G861 C polymorphism differed significantly between Afrikaner OCD patients and healthy controls, with more C-homozygotes observed in this patient subgroup ${ }^{51}$, and, (ii) interestingly, although variants in the 5- $\mathrm{HT}_{2 \mathrm{~A}}$ gene were not found to be associated with $\mathrm{OCD}$ in the abovementioned studies, the T-allele of the T102C variant was found to be associated with trichotillomania in South African patients. ${ }^{56}$ Trichotillomania is a psychiatric disorder that is characterised by repetitive pulling of hair, which may have a biological overlap with OCD. ${ }^{56}$ The MAO-A gene encodes the monoamine oxidase A enzyme, which degrades neurotransmitters such as serotonin, norepinephrine and dopamine. Limited OCD-susceptibility association studies have been performed on MAO-A, yet studies outside of South Africa have shown that the low activity $\mathrm{C}$-variant of the MAO- $\mathrm{A}$ Cl460T polymorphism may be associated with OCD in female patients from North America. ${ }^{62,63}$ In addition, Lochner et al. ${ }^{51}$ replicated this sex-specific finding, which may be partially explained by the location of MAO-A on the X chromosome, in a cohort of South African Caucasian OCD patients.

The dopamine system has also been implicated in the pathophysiology of OCD, as well as other neuropsychiatric phenotypes such as schizophrenia and bipolar disorder. ${ }^{44,64,65}$ The catechol-O-methyltransferase gene (COMT) is therefore an attractive $\mathrm{OCD}$-candidate gene since it encodes a catabolic dopamine enzyme. The gene has been extensively studied in psychiatric genetics ${ }^{66-68}$, with the majority of association studies genotyping a functional polymorphism that causes a 3-4 fold reduction in enzymatic activity (i.e. Vall58Met). ${ }^{69}$ Studies of the South African Caucasian OCD population have identified this polymorphism as a risk factor for both the disorder ${ }^{48}$ and certain symptom dimensions within OCD. ${ }^{55,58}$ The low activity 158Met allele was found to be correlated with more severe symptomatology associated with hoarding in male Afrikaner OCD patients ${ }^{55}$ and in a subsequent study, a cluster of symptoms in South African Caucasian OCD patients that included "symmetry and ordering". 58 The sexual dimorphism detected with COMT 158Met and the hoarding symptom dimension of OCD by Lochner et al. ${ }^{55}$ has also been observed with regards to this polymorphism and susceptibility to the disorder. A metaanalysis of COMT-OCD genetic association studies showed that the 158Met allele is associated with OCD in men $(\mathrm{P}<0.001)^{66}$, making this polymorphism one of the most convincing genetic risk factors for OCD identified to date.

Besides the genes discussed above, polymorphisms in other genes have also been studied in South African OCD populations. A 48 bp variable number of tandem repeats (VNTR) polymorphism of the dopamine receptor D4 gene (DRD4) was associated with age of OCD onset in South African Caucasians. ${ }^{53}$ Furthermore, contrasting associations are often detected, as seen for the Val66Met variant of the brain-derived neurotrophic factor gene (BDNF) in South African OCD patients. The 66Met allele was originally associated, in males, with an earlier age of onset as well as OCD-susceptibility. ${ }^{70}$ However, in a subsequent study, which expanded on the patient cohort used by Hemmings et al. ${ }^{70}$ with Caucasian samples from the Netherlands, Katerberg et al. ${ }^{71}$ found that the Met66Met genotype was associated with a later age of onset in females. These contradictory findings epitomise the results obtained from many psychiatric genetic association studies and reflect the difficulty in obtaining clinically-relevant findings. Polymorphisms in the DAT, DRD 1 and $\mathrm{TH}$ genes have also been investigated ${ }^{50-56,58}$, but have not been associated with any OCD-related trait in South African samples, although these results should be interpreted with caution as only single polymorphisms were genotyped in each of the genes and the sample sizes of the studies were relatively small (e.g. number of OCD patients genotyped ranged from 48 to 250). ${ }^{49,56}$ Furthermore, some of the significant findings reported in Tables II and III may have been caused by type I error due to multiple testing.

\section{Bipolar disorder}

Bipolar disorder is an affective mood disorder, which displays heterogeneous symptomatology and is broadly classified into two main types - bipolar I disorder and bipolar II disorder. ${ }^{72}$ Patients with bipolar I disorder have at least one major manic episode, while bipolar II disorder is characterised by a milder form of mania. Major depressive episodes are found in both forms of the disorder. An overlap in clinical features exists between bipolar disorder and schizophrenia, and it is believed that the two disorders share a large proportion of genetic risk factors. ${ }^{73}$ Research into the genetic component of bipolar disorder in South African populations has been predominantly performed by Savitz and colleagues, using a cohort of Caucasian families, mostly of Afrikaner and British descent (approximately 47 pedigrees of 350 samples). ${ }^{74-80}$ Many of these studies have focussed on gene-environment interactions with potential endophenotypes or intermediate traits. As mentioned previously, the use of endophenotypes in this manner reduces reliance on heterogeneous DSM diagnoses and therefore potentially simplifies the identification of genetic susceptibility factors. ${ }^{77}$ However, when interpreting the results of these studies, the effects of multiple testing which may cause false positive associations 
should be considered, as a number of variables have been analysed in a single study cohort.

Linkage studies in this South African cohort employed a targeted approach, focussing on putative bipolarsusceptibility loci. Linkage to the disorder was detected on three chromosomal regions using a broad diagnosis model (Table II), which included, in addition to bipolar disorder, individuals with other psychiatric disorders. ${ }^{74}$ The same set of markers was used to examine linkage to a potential endophenotype, neurocognitive function, yet none of these markers reached statistical significance in the entire cohort. ${ }^{77}$ However, in one of the Afrikaner pedigrees, a region on chromosome 22q appeared to be associated with this endophenotype. This chromosomal region harbours the COMT gene, discussed in the preceding section, although the Val158Met polymorphism itself was not found to be associated with this endophenotype. This indicates that another polymorphism in this gene, or another gene in the region, could account for linkage to the chromosome $22 q$ region. In other studies of this South African bipolar disorder cohort, the Val158Met polymorphism of COMT was found to:

(i) influence dissociation when previous childhood abuse was taken into account ${ }^{78}$; (ii) indirectly impact schizotypal personality traits as a result of childhood trauma ${ }^{80}$ and (iii) possibly be implicated in right handedness and by proxy, brain lateralisation ${ }^{76}$, although this final finding is debatable.

Further associations with gene-environment interactions and traits of interest have been detected within this South African bipolar disorder cohort. The extensively-researched psychiatric candidate gene, BDNF, was found to influence neurocognitive performance when combined with childhood sexual trauma. ${ }^{75}$ The low activity 66Met allele of the BDNF gene and the Alzheimer's disease-related $\varepsilon 4$ allele of the APOE gene were both found to reduce cognitive performance, when childhood trauma was accounted for. ${ }^{75}$ Contrastingly, in another study of this cohort, the 66Met allele was found to interact with childhood abuse and decreased levels of dissociation. ${ }^{78}$ These inconsistent findings and those mentioned earlier in this review may be explained if the BDNF Val66Met polymorphism is in partial LD with an unobserved causal variant in certain populations. A recent population genetics study of the BDNF locus reinforced this hypothesis by detecting substantial inter-population haplotype diversity as well as observing positive selection at this region. ${ }^{81}$

In concordance with psychiatric research into the genetic architecture of OCD and schizophrenia in South African patients, additional candidate genes from neurotransmitter systems have also been investigated in bipolar disorder. Polymorphisms in the DRD4 and MAO-A genes were found to be associated with the neurocognitive endophenotype of memory. ${ }^{77}$ In a genetic association study using ten candidate endophenotypes in the South African bipolar disorder studies, the most significant finding was that a VNTR in the 3 ' untranslated region of the dopamine transporter gene (SLC6A3) was associated with self-directedness $(\mathrm{P}<0.0001) .{ }^{79}$ However, the relationship between genetic variation in SLC6A3 and personality endophenotypes of bipolar disorder remains poorly understood and should first be replicated before biological conclusions are drawn.

Finally, polymorphisms in three glutamatergic genes,
GRIN2B (rs 1019385), GRM3 (rs6465084) and DAOA (rs701567), were investigated with regards to susceptibility to bipolar disorder and phenotype severity in a populationbased case-control study. ${ }^{82}$ The cohort used in this study differs from the previous South African bipolar disorder studies as in addition to Caucasian samples, individuals from the Cape Mixed Ancestry population were also included. Part of the rationale behind investigating glutamatergic genes is based on neuropharmacological data, as lithium, which forms the cornerstone of the pharmaceutical treatment of bipolar disorder, affects neurotransmitter systems and has been found to influence the glutamate receptors (for a review, see McCarthy et al. ${ }^{83}$ ). None of the SNPs genotyped by Dalvie et al. ${ }^{82}$ were associated with susceptibility to the disorder, but the G-allele of the GRIM3 variant appeared to be associated with a tendency for carriers to develop psychotic symptoms (i.e. four times greater risk). Furthermore, a gene-gene interaction was detected between the GRIN2B and DAOA SNPs, which significantly influenced the risk of hospitalisations due to mania. The functionality of the glutamatergic SNPs analysed in the study, however, remains to be elucidated in future studies as they fall within non-coding regions and were selected on the basis of previous associations with psychotic disorders. ${ }^{82}$

\section{Psychiatric pharmacogenetics in South Africa}

Pharmacogenetics is a field of research that has grown tremendously over the last two decades and involves the investigation of the genetic determinants of drug response. Pharmacogenomic research has arisen more recently as a term coined to mark the transition from the research of individual pharmacogenetic genes/alleles towards holistic studies that focus on the entire genome and are aided by the use of high throughput technologies (e.g. DNA microarrays). We have previously reviewed the status of pharmacogenetic and pharmacogenomic research in South Africa. ${ }^{84}$ This section of the paper will therefore focus on the applications of such technologies in psychiatric settings in South Africa.

A recent review highlighted that the overwhelming majority of psychiatric pharmacogenetic studies have been performed in Caucasian and Asian populations ${ }^{85}$, indicating the need for research that includes the genetically and ethnically diverse African populations. Due to the complex genetic nature of African populations, the majority of pharmacogenetics-related studies have focussed on determining the baseline allele frequencies of relevant pharmacogenetic genes in local South African populations. As can be seen in Figure 1, many of these functional pharmacogenetic alleles differ substantially between populations. ${ }^{86-96}$ For example, the *1B allele of the CYP3A4 gene, which metabolises the majority of clinically available drugs, occurs at a much higher frequency in African individuals.86,88,94 This may have profound implications for African individuals, as they remain underrepresented in pharmacogenetic and genomic research and a great deal of functional variation remains undocumented. ${ }^{8}$ The CYP3A4 gene forms part of the cytochrome P450 (CYP) gene family, which encode a group of polymorphic Phase I drug metabolising enzymes that have formed the basis of a large number of pharmacogenetic candidate gene studies. ${ }^{97}$

Antipsychotic treatment forms the basis of the 


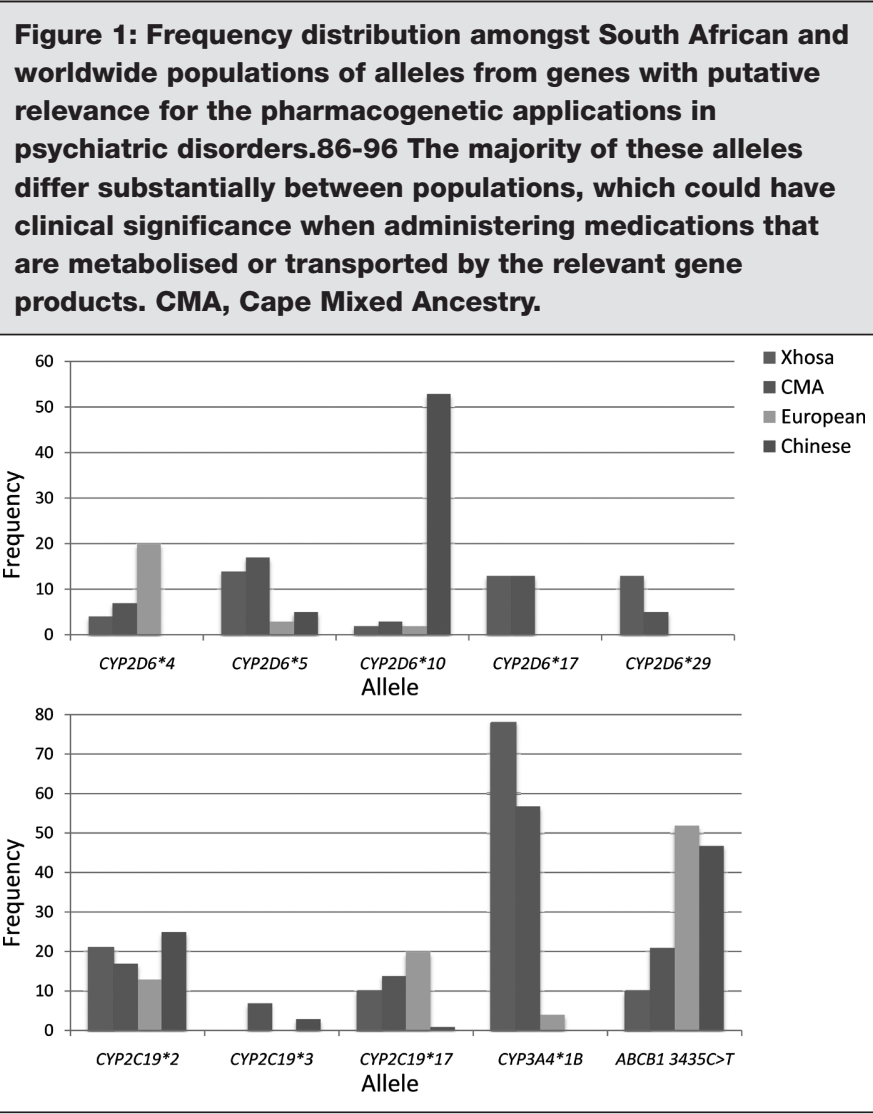

pharmacotherapy of schizophrenia, yet is associated with severe forms of ADRs and the subsequent non-compliance of patients. ${ }^{98}$ The first generation antipsychotics tend to induce extrapyramidal symptoms such as tardive dyskinesia, while the second generation antipsychotics are known to cause severe weight gain or metabolic effects. ${ }^{99}$ Clozapine which is used in cases of treatment-resistant schizophrenia, has been associated with agranulocytosis, which can be fatal in certain cases. ${ }^{100}$ Additionally, the SSRIs which are used to treat OCD may cause side effects such as weight gain, insomnia and sexual dysfunction. ${ }^{85}$ With regards to the treatment of bipolar disorder with lithium, the mood stabiliser has a narrow therapeutic index and has been known to affect renal and thyroid function in certain patients. ${ }^{83}$

The role of pharmacogenetics with regards to antipsychotic treatment has recently been reviewed by Zhang and Malhotra. ${ }^{101}$ There is an overlap in candidate genes for schizophrenia and antipsychotic pharmacogenetics (e.g. COMT, SLC6A4 and the 5-HT and DRD genes), as the neurotransmitter systems potentially involved in the pathophysiology of the disorder may be interlinked to those responsible for the therapeutic effects of antipsychotic treatment.

The CYP2D6 gene has been extensively studied in psychiatric pharmacogenetic research as it is involved in the metabolism of many antipsychotics and antidepressants. ${ }^{102}$ Novel CYP2D6 alleles have been detected in the South African Xhosa and Cape Mixed Ancestry population., 91,95 The presence of rare variants such as these may in part explain the discordance between genotype and phenotype observed in African individuals. Furthermore, the non- functional CYP2D6 allele frequency in the Xhosa schizophrenia population appears to be approximately 25\%, which contributes to the fact that around $12.5 \%$ of schizophrenia patients of this ethnicity fall on the extreme ends of the phenotypic spectrum (i.e. individuals who possess no functional copies of the gene or carry more than two functional copies of the gene and are thus likely to experience ADRs or treatment inefficacy, respectively). ${ }^{95}$ Other pharmacogenetic research in the Xhosa schizophrenia population has revealed a potential association between the MnSOD Ala9Val genotype and the development of abnormal involuntary movements and/or tardive dyskensia in these individuals. ${ }^{40}$ These results, however, remain to be replicated in other African schizophrenia populations.

With regards to the treatment of OCD with SSRIs, studies in South African populations have also revealed differences in the frequencies of functional variation in genes that may be relevant for this drug class. The L-allele of the 5-HTTLPR polymorphism of the SLC6A4 gene was observed at an extremely high frequency in the South African Mixed Ancestry and African populations (i.e. 84\% and 86\% respectively, while other worldwide populations range in frequency 19\%-72\%). ${ }^{103}$ This has implications for SSRI therapy, as this allele has been associated with an increase in response to this class of medication. ${ }^{104}$ The CYP2C19 gene is also involved in the metabolism of SSRIs (e.g. citalopram and sertraline). ${ }^{97}$ A study of variation of CYP2C19 in healthy individuals from the South African Xhosa and the Cape Mixed Ancestry populations identified novel alleles which should be included in genotyping panels for pharmacogenetic association studies of CYP2C19 substrates in these individuals. ${ }^{96}$ The ATP-binding cassette (ABC) Bl gene encodes a membrane-associated protein, which transports a wide variety of xenobiotic compounds. The $3435 \mathrm{C}>\mathrm{T}$ polymorphism of this gene has been studied with regard to the SSRI, paroxetine. ${ }^{105}$ In this study, the $\mathrm{C}$ allele of the polymorphism, which is more frequent in African populations (Figure 1), formed part of a haplotype associated with poor response to the SSRI. Future studies could therefore investigate the role that this polymorphism plays with regards to SSRI response in South African OCD patients.

Finally, no research into the pharmacogenetics of lithium response in bipolar disorder has been performed in South African populations to date, although the review of this topic by McCarthy et al. ${ }^{83}$ could serve as a primer for the direction of future research.

\section{Future directions}

This review has highlighted the initial progress that has been made in the field of psychiatric genetic research in South African populations. These findings, however, only scratch the surface of the genomic architecture of psychiatric disorders. This is a global phenomenon, reflecting the complex nature of such disorders. To date, GWAS data from studies of schizophrenia and bipolar disorder have only identified a handful of genetic variants which contribute towards the susceptibility of these two disorders. For example, a meta-analysis of three large schizophrenia GWAS identified one region of genome-wide significance - 
chromosome 6p22.1 106, while a meta-analysis of bipolar GWAS data identified individual SNPs in the CACNAlC and ANK3 genes that passed the significance threshold. ${ }^{107}$ Strong $\mathrm{LD}$ was detected in the region on chromosome 6p22.1, however the exact genes in this region that confer risk to schizophrenia remain to be elucidated. CACNAlC is known to influence neuronal sodium channel activity, while ANK3 encodes an integral adaptor protein for cell membranes, which may provide insight into the association with bipolar disorder. Currently, no comparable GWAS data are available for $O C D$, but considering the findings for the GWAS studies of the other two psychiatric disorders mentioned here, these studies are unlikely to explain a large proportion of the genetic liability for $\mathrm{OCD}$.

It is important to follow up psychiatric GWAS signals in South African patients to determine whether these findings can be extrapolated to these individuals. A significant challenge in replicating GWAS findings is that the frequencies of many significantly associated GWAS variants vary by 20-40 fold between populations and that $\sim 90 \%$ of these types of studies have been performed in European cohorts. ${ }^{108}$ This has implications in all areas of genomic medicine, since the disparity in the number of studies in diverse African populations questions the sensitivity and specificity of genetic tests, which have been designed from European reference assays. It is therefore important to include African individuals in genomic studies to analyse the transferability of risk markers to predict disease or other traits (e.g. drug response) in these populations. ${ }^{109}$

On a global scale, future research into the psychiatric disorders will see the generation of larger GWAS datasets and a consequent increase in our understanding of the biological pathways contributing towards these disorders. ${ }^{110}$ Additionally, whole genomes of psychiatric patients will become available due to advances in sequencing technologies. Applying next generation sequencing technologies in South African populations should be especially beneficial as the full extent of genetic variation in African populations remains to be catalogued. Current GWAS SNP arrays therefore do not necessarily capture the full extent of haplotypic diversity in these individuals and, additionally, the accuracy of imputation algorithms is lowest in African populations, due to the complex LD patterns observed in their genomes. ${ }^{111}$ Consequently, it is important to build local infrastructure to enable the resequencing and analysis of South African genomes within the country. The benefits of analysing genetic diversity in these individuals using high throughput technologies were clearly illustrated when two genomes and three exomes were generated from five southern African individuals and analysed by Schuster et al. ${ }^{112}$ This study identified over one million novel DNA variants - the highest number of such variants per an individual genome identified to date - yet, currently, these individuals remain the only southern African genome/exome sequences publically available. It will also be important to sequence South African psychiatric patients' exomes and/or genomes in the future as they may possess unique, rare variation not present in healthy individuals. This is relevant, as rare variants may help explain some of the 'missing heritability' which remains undocumented with psychiatric disorders. ${ }^{15}$

Deep resequencing of psychiatric candidate genes or exomes in South African patients using capture-based methodologies in conjunction with next generation sequencing offers an alternative approach to analysing genetic variation in these individuals. If this cannot be achieved due to certain constraints (e.g. financial), future studies should, at least, include more comprehensive genotyping assays than those used in the past and should simultaneously look at additional genes involved in neurotransmitter pathways. Significant associations should be replicated in independent cohorts; alternatively, in vitro functional analyses can be performed if no such cohorts are available. Another area of genomics that requires further investigation is CNV. These types of polymorphisms take up a similar amount of 'genomic real-estate' as SNPs ${ }^{113}$ and rare highly penetrant CNVs are believed to be important in certain psychiatric patients (e.g. chromosome 22q microdeletions and schizophrenia, discussed in preceding sections). Furthermore, another exciting area of research which is believed to be relevant for psychiatric disorders is epigenetics. ${ }^{114}$ This field of research forms the bridge between the genotype and phenotype, investigating changes independent from the underlying DNA sequence. For example, the epigenetic mechanism, DNA methylation, is influenced by exposure to environmental stimuli and can subsequently change the expression patterns of relevant genes in a reversible, yet heritable manner. ${ }^{115}$ Epigenetic variation may therefore explain an additional portion of the 'missing heritability' of complex disorders and warrants further attention. ${ }^{15}$

Future research into the genetic component of psychiatric disorders in South Africa should also strive towards the recruitment of large cohorts of psychiatric patients representing the country's diverse population groups. For example, research into OCD and bipolar disorder in South African cohorts should be performed in populations other than the South African Caucasian population and the Afrikaner subgroup. It is especially important to include the genetically diverse, indigenous African populations in these studies, as this will help elucidate whether genetic susceptibility loci for psychiatric disorders found in one ethnicity are relevant for another. In terms of schizophrenia research, it would be beneficial if patients from additional indigenous African populations other than the Xhosa could be collected. These samples could be utilised to replicate significant results in the Xhosa population, ensuring robust findings that are suitable for translation research.

Samples gathered for these purposes should be stored in biorepositories and electronically linked to detailed clinical data, therefore enabling potential endophenotypes to be investigated in future research. For example, neurophysiological, neuroimaging, and cognitive traits could be studied and thereby replace dichotomous classification of disease status. Comprehensive data regarding pharmacological treatment as well as the occurrence of ADRs would permit large-scale pharmacogenetic studies to be performed. Future psychiatric genetic studies could also investigate the genomic architecture of psychosis and the overlap between schizophrenia and bipolar disorder Furthermore, genetic studies of psychiatric disorders that show an elevated prevalence in the country compared to other areas in the world are required. For example, 
methamphetamine (known by its local street name, 'Tik") addiction occurs at an alarmingly high frequency in the Western Cape, South Africa. ${ }^{116}$ Additionally, psychiatric disorders that place a considerable burden on South African society which have not been studied, such as unipolar depression, require attention. ${ }^{12}$

Before new pharmacogenetic studies are conducted in South Africa, the phenotypes of drug efficacy or ADRs need to be defined. Future pharmacogenetic studies in the psychiatric setting should aim to limit phenotypic heterogeneity and thus reduce the influence of confounding factors. For example, drug-drug interactions encountered with concomitant treatments (frequently employed in psychiatric patient management) can influence drug response and/or ADR. ${ }^{117}$ A high level of antipsychotic polypharmacy (28.6\%) has been documented in South African Xhosa schizophrenia patients treated in the Western Cape, South Africa, which was more than double that observed in sites in the US. ${ }^{118}$ Additionally, prescription patterns varied widely between the different hospitals in this study, emphasising the importance of the standardisation of treatment protocols, especially for research involving patients recruited from more than one study site. Compliance can also adversely affect the outcome of pharmacogenetic studies, specifically in studies involving psychiatric outpatients. Pharmacogenomic phenotypes can be improved by homogenizing treatment protocols, clarifying $\mathrm{ADR}$ definitions and setting up procedures that ensure compliance (e.g. prescription monitoring and/or measurement of plasma drug concentration). Study design is therefore imperative to generate clinically relevant findings. More longitudinal studies of patients recruited at their first clinical intervention who are placed on a standardised treatment regime, preferably incorporating depot injections to ensure compliance, are therefore required. Further information on the steps necessary to establish efficient pharmacogenetic studies in large cohorts of patients in South Africa can be found in an article by Warnich et al. ${ }^{84}$

\section{Conclusion}

The field of psychiatric genetics remains under-utilised in South Africa, as highlighted in preceding sections of this review. In comparison, South Africa boasts one of the largest diamond industries in the world, yet traditionally large numbers of rough diamonds have been sent overseas for cutting, reflecting a loss of potential capital and job creation in the country. This mirrors the field of genomics in the country South Africa has access to some of the most genetically diverse populations and patient cohorts in the world, however limited research has been performed within the country and DNA samples have frequently been sent abroad to be analysed by foreign researchers. It is therefore imperative to create infrastructure to perform large scale psychiatric genetic studies on local soil. Various other aspects, such as the ethical, legal and social implications for performing research in local communities need to be addressed. Although beyond the scope of this review, relevant aspects to be considered include genomic sovereignty (reviewed by Slabbert \& Pepper ${ }^{119}$ ) and cultural sensitivity towards involvement in genetic/genomic studies. Additionally, it will be important to educate the South African public, psychiatrists and medical students with regards to psychiatric genetics and pharmacogenetics. Performing such studies in South African populations will hopefully allow the communities that have provided valuable samples for research to benefit from pharmacogenetic treatment regimes as well as potential royalties in the future, so that the research remains mutually beneficial. Developing the culture of psychiatric genetic research in South Africa will allow the country to contribute towards the global arena of this form of research and potentially help alleviate the country's burden of disease as a result of psychiatric disorders.

\section{Acknowledgements}

The authors would like to acknowledge the South African National Research Foundation as well as Stellenbosch University for providing funding for our work in psychiatric genetics.

\section{References}

1. Soteriades ES, Rosmarakis ES, Paraschakis K, Falagas ME. Research contribution of different world regions in the top 50 biomedical journals (1995-2002). FASEB J 2006 20: 29-34.

2. Uthman $O A$, Uthman MB. Geography of Africa biomedical publications: an analysis of 1996-2005 PubMed papers. Int J Health Geogr 2007; 10:46-56.

3. Hofman KJ, Kanyengo CW, Rapp BA, Kotzin S. Mapping the health research landscape in Sub-Saharan Africa: a study of trends in biomedical publications. J Med Libr Assoc 2009 97:41-4

4. Patel V, Sumathipala A. International representation in psychiatric literature: survey of six leading journals. Br J Psychiatry 2001; 178:406-9.

5. Patel V, Kim YR. Contribution of low- and middle-income countries to research published in leading general psychiatry journals, 20022004. Br J Psychiatry 2007; 190:77-8

6. Jenkins T. Medical genetics in South Africa. J Med Genet 1990; 27 . 760-79.

7. Karayiorgou M, Torrington M, Abecasis GR, Pretorius H, Robertson $B$, Kaliski S et al. Phenotypic characterization and genealogical tracing in an Afrikaner schizophrenia database. Am J Med Genet B Neuropsychiatr Genet 2004; 124:20-8.

8. Tishkoff SA, Reed FA, Friedlaender FR, Ehret C, Ranciaro A, Froment $A$ et al. The genetic structure and history of Africans and African Americans. Science 2009; 324:1035-44.

9. Nurse GT, Weiner JS, Jenkins T. 1985. The Khoi as migrants and nomads. In: The peoples of Southern Africa and their Affinities. (ed. G.A. Harrison), p81-83. Oxford: Clarendon Press.

10. Stein DJ, Seedat S, Herman A, Moomal H, Heeringa SG, Kessler RC et al. Lifetime prevalence of psychiatric disorders in South Africa. Br J Psychiatry 2008; 192:112-7.

11. Seedat S, Stein DJ, Herman A, Kessler R, Sonnega J, Heeringa S et al. Twelve-month treatment of psychiatric disorders in the South African Stress and Health Study (World Mental Health Survey Initiative). Soc Psychiatry Psychiatr Epidemiol 2008; 43:889-97.

12. Norman R, Bradshaw D, Schneider M, Pieterse D, Groenewald P. Revised Burden of Disease Estimates for the Comparative Risk Factor Assessment, South Africa 2000. Methodological Note. Cape Town: South African Medical Research Council, 2006.

13. Mehta U, Durrheim DN, Blockman M, Kredo T, Gounden R, Barnes KI. Adverse drug reactions in adult medical inpatients in a South African hospital serving a community with a high HIVIAIDS prevalence: prospective observational study. Br J Clin Pharmacol 2008; 65:396-406 
14. Lazarou J, Pomeranz BH, Corey PN. Incidence of adverse drug reactions in hospitalized patients: a meta-analysis of prospective studies. JAMA 1998; 279:1200-5

15. Manolio TA, Collins FS, Cox NJ, Goldstein DB, Hindorff LA, Hunter $D J$ et al. Finding the missing heritability of complex diseases. Nature 2009; 461:747-53.

16. Van Os J, Kapur S. Schizophrenia. Lancet 2009; 374:635-45.

17. Riley BP, Rajagopalan S, Mogudi-Carter M, Jenkins T, Williamson R. No evidence for linkage of chromosome $6 p$ markers to schizophrenia in southern African Bantu-speaking families. Psychiatr Genet 1996a; 6:41-49.

18. Riley B, Mogudi-Carter M, Jenkins T, Williamson R. No evidence for linkage of chromosome 22 markers to schizophrenia in southern African Bantu-speaking families. Am J Med Genet 1996b; 67:515-22.

19. Riley BP, Tahir E, Rajagopalan S, Mogudi-Carter M, Fauré S, Weissenbach J et al. A linkage study of the N-methyl-D-aspartate receptor subunit gene loci and schizophrenia in southern African Bantu-speaking families. Psychiatr Genet 1997a; 7:57-74.

20. Riley BP, Williamson R. Non-parametric analysis of chromosome 6p24-22 marker data and schizophrenia in southern African Bantuspeaking families. Psychiatr Genet 1997b; 7:1 31-2.

21. Riley BP, Lin MW, Mogudi-Carter M, Jenkins T, Williamson R, Powell JF et al. Failure to exclude a possible schizophrenia susceptibility locus on chromosome 13q14.1-q32 in southern African Bantuspeaking families. Psychiatr Genet 1998; 8:155-62.

22. Riley BP, Makoff A, Mogudi-Carter M, Jenkins T, Williamson R, Collier $D$ et al. Haplotype transmission disequilibrium and evidence for linkage of the CHRNA7 gene region to schizophrenia in Southern African Bantu families. Am J Med Genet 2000; 96:196-201.

23. Javitt DC, Zukin SR. Recent advances in the phencyclidine model of schizophrenia. Am J Psychiatry 1991; 148:1301-8.

24. Freedman R, Coon H, Myles-Worsley M, Orr-Urtreger A, Olincy A, Davis $A$ et al. Linkage of a neurophysiological deficit in schizophrenia to a chromosome 15 locus. Proc Natl Acad Sci U S A 1997; 94:587-92

25. Ng MY, Levinson DF, Faraone SV, Suarez BK, DeLisi LE, Arinami T et al. Meta-analysis of 32 genome-wide linkage studies of schizophrenia. Mol Psychiatry 2009; 14:774-85.

26. Hall D, Wijsman EM, Roos JL, Gogos JA, Karayiorgou M. Extended intermarker linkage disequilibrium in the Afrikaners. Genome Res 2002; 12:956-961.

27. Abecasis GR, Burt RA, Hall D, Bochum S, Doheny KF, Lundy SL et al. Genomewide scan in families with schizophrenia from the founder population of Afrikaners reveals evidence for linkage and uniparental disomy on chromosome 1. Am J Hum Genet 2004; 74:403-417.

28. Liu H, Abecasis GR, Heath SC, Knowles A, Demars S, Chen YJ et al. Genetic variation in the $22 q 11$ locus and susceptibility to schizophrenia. Proc Natl Acad Sci USA 2002; 99:16859-16864.

29. Xu B, Woodroffe A, Rodriguez-Murillo L, Roos JL, van Rensburg EJ, Abecasis GR et al. Elucidating the genetic architecture of familial schizophrenia using rare copy number variant and linkage scans. Proc Natl Acad Sci U S A 2009; 106:16746-51.

30. Kobrynski LJ, Sullivan KE. Velocardiofacial syndrome, DiGeorge syndrome: the chromosome 22q1 1.2 deletion syndromes. Lancet 2007; 370:1443-1452.

31. Murphy KC, Jones LA, Owen MJ. High rates of schizophrenia in adults with velo-cardio-facial syndrome. Arch Gen Psychiatry 1999; 56:940-5

32. Bassett AS, Marshall CR, Lionel AC, Chow EW, Scherer SW. Copy number variations and risk for schizophrenia in 22q11.2 deletion syndrome. Hum Mol Genet 2008; 17:4045-53.

33. Wiehahn GJ, Bosch GP, du Preez RR, Pretorius HW, Karayiorgou M, Roos JL. Assessment of the frequency of the 22 ql 1 deletion in Afrikaner schizophrenic patients. Am J Med Genet B Neuropsychiatr Genet 2004; 15:20-2.

34. Xu B, Roos JL, Levy S, van Rensburg EJ, Gogos JA, Karayiorgou M. Strong association of de novo copy number mutations with sporadic schizophrenia. Nat Genet 2008; 40:880-5.

35. Roos JL, Pretorius HW, Karayiorgou M. Clinical characteristics of an Afrikaner founder population recruited for a schizophrenia genetic study. Ann NY Acad Sci 2009; 1151:85-101

36. Niehaus DJ, Koen L, Muller J, Laurent C, Stein DJ, Lochner C et al. Obsessive compulsive disorder--prevalence in Xhosa-speaking schizophrenia patients. S Afr Med J 2005; 95:120-2

37. Seedat F, Roos JL, Pretorius HW, Karayiorgou M, Nel B. Prevalence and clinical characteristics of obsessive-compulsive disorder and obsessive compulsive symptoms in Afrikaner schizophrenia and schizoaffective disorder patients. Afr J Psychiatry (Johannesbg) 2007; 10:219-24.

38. Koen L. Chromosomal aberrations in the Xhosa schizophrenia population. Thesis, Stellenbosch University 2008; available online http://hdl.handle.net/10019/1697.

39. Laurent $C$, Niehaus D, Bauché S, Levinson DF, Soubigou S, Pimstone S et al. CAG repeat polymorphisms in KCNN3 (HSKCa3) and PPP2R2B show no association or linkage to schizophrenia. Am J Med Genet B Neuropsychiatr Genet 2003; 11 6B:45-50.

40. Hitzeroth A, Niehaus DJ, Koen L, Botes WC, Deleuze JF, Warnich L. Association between the MnSOD Ala-9Val polymorphism and development of schizophrenia and abnormal involuntary movements in the Xhosa population. Prog Neuropsychopharmacol Biol Psychiatry 2007; 31:664-72.

41. Gottesman II, Gould TD. The endophenotype concept in psychiatry: etymology and strategic intention. Am J Psychiatry 2003; 160:63645.

42. Leppänen JM, Niehaus DJ, Koen L, Du Toit E, Schoeman R, Emsley $R$ Emotional face processing deficit in schizophrenia: A replication study in a South African Xhosa population. Schizophr Res 2006; 84:323-30.

43. Leppänen JM, Niehaus DJ, Koen L, Du Toit E, Schoeman R, Emsley R. Deficits in facial affect recognition in unaffected siblings of Xhosa schizophrenia patients: evidence for a neurocognitive endophenotype. Schizophr Res 2008; 99:270-3.

44. Stein DJ. Obsessive-compulsive disorder. Lancet. 2002; 360:397-405.

45. Van Grootheest DS, Cath DC, Beekman AT, Boomsma DI. Twin studies on obsessive-compulsive disorder: a review. Twin Res Hum Genet 2005; 8:450-8.

46. Nicolini H, Arnold P, Nestadt G, Lanzagorta N, Kennedy JL. Overview of genetics and obsessive-compulsive disorder Psychiatry Res 2009; 30; 170:7-14.

47. Kinnear CJ, Niehaus DJ, Moolman-SmookJC, du Toit PL, van Kradenberg J, Weyers JB et al. Obsessive-compulsive disorder and the promoter region polymorphism (5-HTTLPR) in the serotonin transporter gene (SLC6A4): a negative association study in the Afrikaner population. Int J Neuropsychopharmacol 2000; 3:327-331

48. Niehaus DJ, Kinnear CJ, Corfield VA, du Toit PL, van Kradenburg J, Moolman-Smook JC et al. Association between a catechol-omethyltransferase polymorphism and obsessive-compulsive disorder in the Afrikaner population. J Affect Disord. 2001; 65:61-5.

49. Kinnear C, Niehaus DJ, Seedat S, Moolman-Smook JC, Corfield VA, Malherbe $G$ et al. Obsessive-compulsive disorder and a novel polymorphism adjacent to the oestrogen response element (ERE 6) 
upstream from the COMT gene. Psychiatr Genet. 2001; 11:85-7.

50. Hemmings SM, Kinnear CJ, Niehaus DJ, Moolman-Smook JC, Lochner C, Knowles JA et al. Investigating the role of dopaminergic and serotonergic candidate genes in obsessive-compulsive disorder. Eur Neuropsychopharmacol 2003; 13:93-8.

51. Lochner C, Hemmings SM, Kinnear CJ, Moolman-Smook JC, Corfield VA, Knowles JA et al. Gender in obsessive-compulsive disorder: clinical and genetic findings. Eur Neuropsychopharmacol 2004a; 14:437-45.

52. Lochner C, Seedat S, Hemmings SM, Kinnear CJ, Corfield VA, Niehaus DH et al. Dissociative Experiences in ObsessiveCompulsive Disorder and Trichotillomania: Clinical and Genetic Findings. Comp Psychiatry 2004b; 45: 384-91.

53. Hemmings SM, Kinnear CJ, Lochner C, Niehaus DJ, Knowles JA, Moolman-Smook JC et al. Early- versus late-onset obsessivecompulsive disorder: investigating genetic and clinical correlates. Psychiatry Res 2004; 128:175-82.

54. Lochner C, Hemmings SM, Kinnear CJ, Niehaus DJ, Nel DG, Corfield $V A$ et al. Cluster analysis of obsessive-compulsive spectrum disorders in patients with obsessive-compulsive disorder: clinical and genetic correlates. Compr Psychiatry 2005a; 46:14-9.

55. Lochner C, Kinnear CJ, Hemmings SM, Seller C, Niehaus DJ, Knowles JA et al. Hoarding in obsessive-compulsive disorder: clinical and genetic correlates. J Clin Psychiatry 2005b; 66:1 155-60.

56. Hemmings SM, Kinnear CJ, Lochner C, Seedat S, Corfield VA, Moolman-Smook JC et al. Genetic correlates in trichotillomania-- $A$ case-control association study in the South African Caucasian population. Isr J Psychiatry Relat Sci 2006; 43:93-101.

57. Lochner C, Seedat S, Hemmings SM, Moolman-Smook JC, Kidd M, Stein DJ. Investigating the possible effects of trauma experiences and 5-HTT on the dissociative experiences of patients with OCD using path analysis and multiple regression. Neuropsychobiology 2007; 56:6-13.

58. Lochner C, Hemmings SM, Kinnear CJ, Nel D, Hemmings SM, Seedat $S$ et al. Cluster analysis of obsessive-compulsive symptomatology: identifying obsessive-compulsive disorder subtypes. Isr J Psychiatry Relat Sci 2008; 45:164-76.

59. Vythilingum B, Cartwright C, Hollander E. Pharmacotherapy of obsessive-compulsive disorder: experience with the selective serotonin reuptake inhibitors. Int Clin Psychopharmacol 2000; 15: 7-13.

60. Bloch MH, Landeros-Weisenberger A, Sen S, Dombrowski P, Kelmendi B, Coric $V$ et al. Association of the serotonin transporter polymorphism and obsessive-compulsive disorder: systematic review. Am J Med Genet B Neuropsychiatr Genet 2008; 147: 850-8.

61. Heils A, Teufel A, Petri S, Stober G, Riederer P, Bengel D et al. Allelic variation of human serotonin transporter gene expression. $J$ Neurochem 1996; 66:2621-24.

62. Camarena B, Cruz C, de la Fuente JR, Nicolini H. A higher frequency of a low activity-related allele of the MAO-A gene in females with obsessive-compulsive disorder. Psychiatr Genet 1998; 8:255-7.

63. Camarena B, Rinetti G, Cruz C, Gómez A, de La Fuente JR, Nicolini $H$. Additional evidence that genetic variation of MAO-A gene supports a gender subtype in obsessive-compulsive disorder. Am J Med Genet 2001; 8:279-82.

64. Goodman WK, MCDougle CJ, Lawrence LP, Price LH, Riddle MA, Pauls DL, Leckman JF. Beyond the serotonin hypothesis: a role for dopamine in some forms of obsessive compulsive disorder. J Clin Psychiatry 1990; 51 (suppl): 36-43.

65. Cousins DA, Butts K, Young AH. The role of dopamine in bipolar disorder. Bipolar Disord 2009; 11:787-806.

66. Pooley EC, Fineberg N, Harrison PJ. The met(158) allele of catechol-O-methyltransferase (COMT) is associated with obsessive-compulsive disorder in men: case-control study and meta-analysis. Mol Psychiatry 2007; 12:556-61

67. Zhang Z, Lindpaintner K, Che R, He Z, Wang P, Yang P. The Val/Met functional polymorphism in COMT confers susceptibility to bipolar disorder: evidence from an association study and a meta-analysis. J Neural Transm 2009; 11 6:1 193-200.

68. Costas J, Sanjuán J, Ramos-Ríos R, Paz E, Agra S, Ivorra JL. Heterozygosity at catechol-O-methyltransferase Vall 58Met and schizophrenia: New data and meta-analysis. J Psychiatr Res 2010 (doi:10.1016/j.jpsychires.2010.04.021).

69. Weinshilboum RM, Raymond FA. Inheritance of low erythrocyte catechol-o-methyltransferase activity in man. Am J Hum Genet 1977; 29:125-35.

70. Hemmings SM, Kinnear CJ, Van der Merwe L, Lochner C, Corfield $V A$, Moolman-Smook JC et al. Investigating the role of the brainderived neurotrophic factor (BDNF) val66met variant in obsessive-compulsive disorder (OCD). World J Biol Psychiatry 2008; 9:126-34.

71. Katerberg H, Lochner C, Cath DC, de Jonge P, Bochdanovits Z, Moolman-Smook JC et al. The role of the brain-derived neurotrophic factor (BDNF) val66met variant in the phenotypic expression of obsessive-compulsive disorder (OCD). Am J Med Genet Part B 2009; 150:1050-1062.

72. Müller-Oerlinghausen B, Berghöfer A, Bauer M. Bipolar disorder. Lancet 2002; 359:241-7.

73. Lichtenstein P, Yip BH, Bjork C, Pawitan Y, Cannon TD, Sullivan PF et al. Common genetic determinants of schizophrenia and bipolar disorder in Swedish families: a population-based study. Lancet 2009; 373: 234-39.

74. Savitz J, Cupido CL, Ramesar RK. Preliminary evidence for linkage to chromosome 1q31-32, 10q23.3, and 16p13.3 in a South African cohort with bipolar disorder. Am J Med Genet B Neuropsychiatr Genet 2007a; 144B:383-7.

75. Savitz J, van der Merwe L, Stein DJ, Solms M, Ramesar R. Genotype and childhood sexual trauma moderate neurocognitive performance: a possible role for brain-derived neurotrophic factor and apolipoprotein E variants. Biol Psychiatry 2007b; 62:391-9.

76. Savitz J, van der Merwe L, Solms M, Ramesar R. Lateralization of hand skill in bipolar affective disorder. Genes Brain Behav 2007C; 6:698-705.

77. Savitz J, van der Merwe L, Solms M, Ramesar R. A linkage and family-based association analysis of a potential neurocognitive endophenotype of bipolar disorder. Neuromolecular Med 2007d; 9:101-16.

78. Savitz JB, van der Merwe L, Newman TK, Solms M, Stein DJ, Ramesar $R S$. The relationship between childhood abuse and dissociation. Is it influenced by catechol-O-methyltransferase (COMT) activity? Int J Neuropsychopharmacol 2008a; 1 1:149-61.

79. Savitz J, van der Merwe L, Ramesar R. Personality endophenotypes for bipolar affective disorder: a family-based genetic association analysis. Genes Brain Behav 2008b;7:869-76.

80. Savitz J, van der Merwe L, Newman TK, Stein DJ, Ramesar R. Catechol-o-methyltransferase genotype and childhood trauma may interact to impact schizotypal personality traits. Behav Genet 2010; 40:415-23.

81. Petryshen TL, Sabeti PC, Aldinger KA, Fry B, Fan JB, Schaffner SF et al. Population genetic study of the brain-derived neurotrophic factor (BDNF) gene. Mol Psychiatry 2010; 15:810-5. 
82. Dalvie S, Horn N, Nossek C, van der Merwe L, Stein DJ, Ramesar R. Psychosis and relapse in bipolar disorder are related to GRM3, DAOA, and GRIN2B genotype. Afr J Psychiatry (Johannesbg) 2010; 13:297-301.

83. McCarthy MJ, Leckband SG, Kelsoe JR. Pharmacogenetics of lithium response in bipolar disorder. Pharmacogenomics 2010; 11:1439-65.

84. Warnich L, Drögemöller BI, Pepper MS, Dandara C, Wright GE. Pharmacogenomic research in South Africa: lessons learned and future opportunities in the Rainbow Nation. Curr Pharmacogenomics Person Med 2011; 9(3) (in press).

85. Zandi PP, Judy JT. The promise and reality of pharmacogenetics in psychiatry. Psychiatr Clin North Am 2010; 33:181-224.

86. Ball SE, Scatina J, Kao J, Ferron GM, Fruncillo R, Mayer P. Population distribution and effects on drug metabolism of a genetic variant in the 5' promoter region of CYP3A4. Clin Pharmacol Ther 1999; 66:288-94.

87. Ameyaw MM, Regateiro F, Li T, Liu X, Tariq M et al. MDRI pharmacogenetics: frequency of the C3435T mutation in exon 26 is significantly influenced by ethnicity. Pharmacogenetics 2001; 11:217-21.

88. Du J, Xing Q, Xu L, Xu M, Shu A, Shi Y et al. Systematic screening for polymorphisms in the CYP3A4 gene in the Chinese population. Pharmacogenomics 2006; 7:831-41.

89. Gaedigk A, Simon SD, Pearce RE, Bradford LD, Kennedy MJ, Leeder JS. The CYP2D 6 activity score: Translating genotype information into a qualitative measure of phenotype. Clin Pharmacol Ther 2008; 83:234-42.

90. Chen L, Qin S, Xie J, Tang J, Yang L, Shen W et al. Genetic polymorphism analysis of CYP2C1 9 in Chinese Han populations from different geographic areas of mainland China. Pharmacogenomics 2008; 9:691-702.

91. Gaedigk A., Coetsee C. The CYP2D6 gene locus in South African Coloureds: unique allele distributions, novel alleles and gene arrangements. Eur J Clin Pharmacol 2008; 64:465-475.

92. Qin S, Shen L, Zhang A, Xie J, Shen W, Chen L et al. Systematic polymorphism analysis of the CYP2D 6 gene in four different geographical Han populations in mainland China. Genomics 2008; 92:152-8.

93. Ragia G, Arvanitidis KI, Tavridou A, Manolopoulos VG. Need for reassessment of reported CYP2C1 9 allele frequencies in various populations in view of CYP2C19*17 discovery: the case of Greece. Pharmacogenomics 2009; 10:43-9.

94. Parathyras J, Gebhardt S, Hillermann-Rebello R, Grobbelaar N, Venter M, Warnich L. A pharmacogenetic study of CD4 recovery in response to HIV antiretroviral therapy in two South African population group. J Hum Genet 2009; 54:261-5.

95. Wright GE, Niehaus DJ, Drögemöller BI, Koen L, Gaedigk A, Warnich L. Elucidation of CYP2D6 genetic diversity in a unique African population: implications for the future application of pharmacogenetics in the Xhosa population. Ann Hum Genet 2010; 74:340-50.

96. Drögemöller BI, Wright GEB, Niehaus DJ, , Koen L, Malan S, Da Silva $D M$, Hillermann-Rebello $R$ et al. Characterization of the genetic profile of CYP2C1 9 in two South African populations. Pharmacogenomics 2010; 11:1095-103.

97. Ingelman-Sundberg M, Sim SC, Gomez A, Rodriguez-Antona C. Influence of cytochrome $P 450$ polymorphisms on drug therapies: pharmacogenetic, pharmacoepigenetic and clinical aspects Pharmacol Ther 2007; 11 6:496-526.

98. Lieberman JA, Stroup TS, McEvoy JP, Swartz MS, Rosenheck RA, Perkins DO et al. Effectiveness of antipsychotic drugs in patients with chronic schizophrenia. N Engl J Med 2005; 353:1209-23.

99. Leucht S, Corves C, Arbter D, Engel RR, Li C, Davis JM. Secondgeneration versus first-generation antipsychotic drugs for schizophrenia: a meta-analysis. Lancet 2009; 373:31-41.

100. Alvir JM, Lieberman JA, Safferman AZ, Schwimmer JL, Schaaf JA. Clozapine-induced agranulocytosis. Incidence and risk factors in the United States. N Engl J Med 1993; 329:162-7.

101. Zhang JP, Malhotra AK. Pharmacogenetics and antipsychotics: therapeutic efficacy and side effects prediction. Expert Opin Drug Metab Toxicol 2011; 7:9-37.

102. Zanger UM, Raimundo S, Eichelbaum M. Cytochrome P450 2D6: overview and update on pharmacology, genetics, biochemistry. Naunyn-Schmiedeberg's Arch Pharmacol 2004; 369:23-37.

103. Esau L, Kaur M, Adonis L, Arieff Z. The 5-HTTLPR polymorphism in South African healthy populations: a global comparison. J Neural Transm 2008; 1 15:755-60.

104. White K, Walline C, Barker E (2005) Serotonin transporter: implications for antidepressant drug development. Am Assoc Pharm Sci J 7:421-433.

105. Kato M, Fukuda T, Serretti A, Wakeno M, Okugawa G, Ikenaga Y et al. ABCBI (MDRI) gene polymorphisms are associated with the Clinical response to paroxetine in patients with major depressive disorder. Prog Neuropsychopharmacol Biol Psychiatry 2008, 32:398-404.

106. Shi J, Levinson DF, Duan J, Sanders AR, Zheng Y, Pe'er I et al. Common variants on chromosome 6p22.1 are associated with schizophrenia. Nature 2009; 460:753-7.

107. Ferreira MA, O'Donovan MC, Meng YA, Jones IR, Ruderfer DM, Jones $L$ et al. Collaborative genome-wide association analysis supports a role for ANK3 and CACNA1C in bipolar disorder. Nat Genet 2008; 40:1056-8.

108. Rotimi CN, Jorde LB. Ancestry and disease in the age of genomic medicine. N Engl J Med 2010; 363:1551-8.

109. Ng PC, Murray SS, Levy S, Venter JC. An agenda for personalized medicine. Nature 2009; 461:724-6.

110. Kim Y, Zerwas S, Trace SE, Sullivan PF. Schizophrenia genetics: where next? Schizophr Bull 2011; 37:456-63.

111. Marchini J, Howie B. Genotype imputation for genome-wide association studies. Nat Rev Genet 2010; 11:499-511.

112. Schuster SC, Miller W, Ratan A, Tomsho LP, Giardine B, Kasson LR et al. Complete Khoisan and Bantu genomes from southern Africa. Nature 2010; 463:943-7.

113. International HapMap 3 Consortium. Integrating common and rare genetic variation in diverse human populations. Nature 2010; 467:52-8

114. Rutten BP, Mill J. Epigenetic Mediation of Environmental Influences in Major Psychotic Disorders. Schizophr Bull 2009; 35:1045-56.

115. Bonasio R, Tu S, Reinberg D. Molecular signals of epigenetic states. Science 2010; 330:612-6.

116. Kapp C. Crystal meth boom adds to South Africa's health challenges. Lancet 2008; 371:193-4.

117. Arranz MJ, Kapur S. Pharmacogenetics in Psychiatry: Are We Ready for Widespread Clinical Use? Schizophr Bull 2008; 34:11 3044.

1 18. Koen L, Magni P, Niehaus DJ, le Roux A. Antipsychotic prescription patterns in Xhosa patients with schizophrenia or schizoaffective disorder. Afr J Psychiatry (Johannesbg) 2008; 11:287-90.

119. Slabbert MN, Pepper MS. "A room of our own?"' Legal lacunae regarding genomic sovereignty in South Africa. Tydskrif vir Hedendaagse Romeins-Hollandse Reg Journal of Contemporary South African Roman-Dutch Law) 2010; 73:432-450. 